\title{
O SISTEMA NACIONAL DE CULTURA NO GOVERNO DILMA: CONTINUIDADES E AVANÇOS
}

\author{
Alexandre Barbalho \\ Universidade Estadual do Ceará, Brasil
}

\begin{abstract}
Resumo: O propósito desse artigo é analisar como se deu a atuação das ministras de cultura do Brasil Ana de Hollanda e Marta Suplicy no que diz respeito à implantação do Sistema Nacional de Cultura. Para tanto, situa-se os agentes e suas posições nesse processo que diz respeito à institucionalização do campo cultural com forte relação com o campo político. O Estado como detentor de meta-capital é um espaço de convergência e embate entre os diversos campos. Nesse sentido, compreender uma política pública de cultura é levar em consideração os necessários cruzamento de interesses entre agentes do campos cultural e político e aqueles que integram ambos simultaneamente. Minha hipótese é a de que, ao contrário de outras frentes de atuação do MinC, como o Programa Cultura Viva, que sofreram descontinuidades, o processo de implantação do Sistema ganhou um novo impulso no governo Dilma.
\end{abstract}

Palavras-chave: Sistema Nacional de Cultura; Ministério da Cultura; Política Cultural.

\section{Introdução}

A área da cultura como objeto de políticas públicas no Brasil tem sido historicamente relega a planos secundários. As ações e instituições voltadas para o setor sofreram, ao longo das décadas, com as descontinuidades de suas políticas, as restrições financeiras, a deficiência de quadros técnicos, bem como com as relações clientelistas que, se estão presentes em amplos setores do poder público, se fazem mais intensas na cultura decorrentes de fragilidades do campo, o que resulta em maior dependência de seus agentes dos favores provenientes dos gestores governamentais e seus intermediários.

Tal contexto não se modificou na sua estrutura com a criação pelo presidente Sarney do Ministério da Cultura (MinC) em março de 1985, pois o novo órgão surge descapitalizado politicamente, financeiramente e simbolicamente, o que comprova a alta rotatividade de ministros. Entre o seu ano de criação e o fim do governo Itamar Franco, em 1994, foram 8 ministros, sendo que no governo Collor (1990-1992), o MinC foi transformado em uma secretaria que teve, nesse curto espaço de tempo, dois titulares. 
A longa gestão de Francisco Weffort como ministro da Cultura no período da presidência de Fernando Henrique Cardoso (1995-2002) se possibilitou uma certa estabilidade às ações do governo federal, estas foram marcadas, paradoxalmente, por uma espécie de retirada do poder público posto que grande parte do que foi executado se deu por meio de leis de incentivo à cultura, a Lei Rouanet e a do Audiovisual, que transferem à decisão de quanto e onde investir aos departamentos de marketing ou, na melhor das hipóteses, ao gestor cultural das empresas.

Esta realidade foi sendo modificada de forma estrutural nos governos Lula (20032010), com as gestões de Gilberto Gil e Juca Ferreira no MinC, e continua em transformação no governo Dilma (2011-2014), que teve como ministras Ana de Holanda e Marta Suplicy. Se a principal forma de financiamento à cultura continua sendo as leis de incentivo, há um esforço por parte do Ministério em institucionalizar as políticas culturais, não apenas no âmbito federal, mas também nos demais níveis da federação. O objetivo é de que se transformem em políticas de Estado e não apenas de governo e não sofram tantas descontinuidades (Rubim, 2011: 2010).

Um dos instrumentos que se apresenta como fundamental nesse processo é o Sistema Nacional de Cultura (SNC) por sua própria função de, como indica o nome, estabelecer, em conjunto com a sociedade, um sistema federativo de políticas públicas específico para a cultura. Tal sistema, ao exigir a criação de mecanismos mínimos para o seu funcionamento nos estados e municípios do país (órgão gestor específico, conselho, plano e fundo de cultura), possibilita algum grau de efetividade das políticas culturais independente do governo vigente (Barbalho; Barros; Calabre, 2013).

O que proponho nesse artigo é analisar como se deu a atuação das ministras Ana de Hollanda e Marta Suplicy e respectivas equipes no que diz respeito à implantação do SNC durante suas gestões. Para tanto, irei situar os agentes e suas posições nesse processo que diz respeito à institucionalização do campo cultural com forte relação com o campo político. O Estado como detentor de meta-capital, pois concentra não só capital político, mas também econômico, social e cultural, é um espaço de convergência e embate entre os diversos campos (Bourdieu, 2012: 1996). Nesse sentido, compreender uma política pública de cultura é levar em consideração os necessários cruzamento de interesses entre agentes do campos cultural e político e aqueles que integram ambos simultaneamente.

Minha hipótese é a de que, ao contrário de outras frentes de atuação do MinC, como o Programa Cultura Viva, que sofreram descontinuidades, o processo de implantação do Sistema ganhou um novo impulso no governo Dilma. Isto se deveria, entre outras 
causas, ao reforço da corrente a favor do SNC na lógica de poder interna ao Ministério com a saída de agentes ligados aos ministros Gilberto Gil e Juca Ferreira, agentes estes que não priorizaram a implantação do referido programa. Pensando com Norbert Elias (2008), o que ocorreu foi um equilíbrio após um momento de disputas mais acirradas no jogo de relações de poder.

Para alcançar o objetivo proposto, construí um corpus empírico composto de entrevistas com ex-gestores do MinC e de documentos do Partido dos Trabalhadores (PT) e do MinC. A partir da análise desse material, organizei o artigo em duas partes, seguidas de apontamentos conclusivos. Na primeira, traço o percurso do SNC desde quando era ainda uma proposta de governo do então candidato Luís Inácio Lula da Silva até o fim de seu segundo governo. Em seguida, analiso as ações implementadas em torno do referido Sistema nas gestões de Hollanda e Suplicy.

\section{A trajetória do Sistema Nacional de Cultura: de programa à política de governo}

Não há registro de que nas relações entre o Estado e a cultura no Brasil tenha sido esboçada a implantação de um sistema nacional de cultura, o que não implica que o tema não tenha sido discutido em alguns momentos ${ }^{1}$. $\mathrm{O}$ que mais próximo disso ocorreu foi a Política Nacional de Cultura, lançada em 1975, que mencionava a necessidade de articulação entre os governos federal, estaduais e municipais na concretização das políticas no setor (Barbalho, 1998; Cury, 2002).

Portanto, a origem mais imediata do investimento do MinC em prol do SNC desde 2003 deve ser buscada no programa de governo do então candidato Lula. O documento “A imaginação a serviço do país. Programa de Políticas Públicas de Cultura" (Coligação Lula Presidente, 2002) expõe os parâmetros que deveriam nortear a atuação do candidato na área da cultura se eleito. De fato, é um documento valioso para entender as linhas de atuação do Ministério ainda hoje² .

\footnotetext{
${ }^{1}$ Márcio Meira e Gustavo Gazzinelli (2006), por exemplo, informam que em 1976, o Conselho Federal de Cultura realizou em Salvador o Encontro Nacional de Cultura, cujo tema geral foi "Sistema Nacional de Cultura”, abordado em sessões sobre Sistema Nacional de Arquivos, Integração Regional e Regionalização Cultural, Sistema Nacional de Bibliotecas, Sistema Mueológico Brasileiro e Proposições para a Política de Integração Nacional de Cultura.

${ }^{2}$ Entre as pessoas que colaboraram com a redacão do caderno temático da cultura encontram-se futuros gestores do MinC, tanto nos governos Lula, quanto no de Dilma: Antonio Grassi, Roberto Peixe, Márcio Meira, Margarete Moraes, Sérgio Mamberti, que eram da equipe de coordenadores de redacão do documento, além de Aloysio Guapindaia, Ângelo Osvaldo, Bernardo da Matta Machado, José do Nascimento Junior, Marta Porto, Ricardo Lima e Vítor Ortiz.
} 
O Programa foi antecedido por uma série de encontros promovidos pelos militantes do PT ligados à cultura no sentido de recolher e refletir sobre as experiências desenvolvidas nas gestões municipais petistas, ou seja, no esforço de estabelecer o que seria o "modo petista" de governar na área da cultura3. Tais encontros acabaram por envolver também os militantes de outros partidos que faziam parte do arco de alianças que sustentava tais gestões, como o Partido Comunista do Brasil (PCdoB) e o Partido Socialista Brasileiro (PSB).

Como recorda Márcio Meira em entrevista concedida à pesquisadora Ana Lúcia Aragão, esse esforço de sistematização ocorreu em 2001 e resultou em um encontro em São Paulo, apoiado pela Fundação Perseu Abramo, ligada ao PT. O objeto era "construir um projeto político mais integrado e nacional”:

Porque nós tínhamos projetos locais, mas não tinha um projeto nacional, embora nós tenhamos tido projetos em 1994, 1989 nos programas do Lula né, pra presidente, eram bons programas, mas eram muito incipientes em termo de prática, de experiência prática de governo. Em 2001 não, nós já estávamos no nível de maturidade, porque já tínhamos experiência, tinha governado 8 anos, 10 anos, 12 anos prefeituras de importantes capitais (Meira apud Aragão, 2013: 127).

Do Programa, irei extrair apenas a discussão mais centrada em torno do "sistema nacional de política cultural", proposto no documento, pois são muitos os elementos que fazem referência à lógica federativa e sistêmica passíveis de serem incorporados ao debate. Para ser ter uma ideia, já na apresentação, assinada pelo Coordenador do Programa de Governo, Antônio Palocci Filho, está expresso o direito à cultura como direito básico e republicano.

"Gestão Democrática" é um dos seis temas que organizam o documento. Nele se encontram, entre outras, as propostas de implantação da Política Nacional de Cultura (PNC) e do Sistema Nacional de Política Cultural (SNPC). Especificamente sobre o segundo, defende-se que deve ser implantado segundo as "precrições constitucionais" de modo a garantir a "efetivação de políticas públicas de cultura de forma integrada e democrática, em todo o país, incluindo aí, especialmente, a rede escolar" (Coligação Lula Presidente, 2002: 20).

O SNPC é entendido como fundamental para a descentralização da PNC, pois integraria não apenas as três esferas de governo, mas também as instituições privadas e do terceiro setor. Integrar o Sistema seria a condição prévia para que qualquer instituição,

3 O documento cita especificamente as cidades de Porto Alegre, Belém, Campo Grande e Recife. 
pública ou privada, acessasse recurso do Fundo Nacional de Cultura (FNC). Com isso, os recursos obtidos por meio do SNPC deveriam ser feito pelos conselhos de cultura de cada esfera, posto que a sua existência era um dos pré-requisitos de integração no Sistema.

Ainda no âmbito da gestão, o documento prevê a definição de Instituições Nacionais de Referência Cultural que seriam responsáveis pela formacão na área cultural, nos mais diversos segmentos artísticos, incluindo capacitacão para os técnicos da gestão cultural nas três esferas. Este processo formativo permanente é considerado essencial para o fortalecimento do SNPC, de modo que as instituições devem ser "criteriosamente selecionadas e integradas ao Sistema, de tal forma a que atendam demandas de regiões do país desassistidas de pessoal qualificado para desenvolver localmente políticas públicas de cultura" (Coligação Lula Presidente, 2002: 21).

Antes, o documento já tinha afirmado que a política cultural a ser adotada deveria garantir "a abertura dos canais institucionais e financeiros, por meio da constituição do Sistema Nacional de Política Cultural, a amplos setores tradicionalmente atendidos pelas “políticas de recorte social ou assistencialistas”" (Coligação Lula Presidente, 2002: 16).

Tais propostas, a saber, a criação de um plano e de um sistema de cultura, a elaboração de uma política de formação de gestores e a participação da sociedade, além dos entes da federação, como veremos, pautaram a atuação dos agentes envolvidos com o SNC do primeiro governo Lula ao governo Dilma.

Logo após a eleição de Lula, começaram as especulações em torno de quem assumiria o MinC. Tudo indicava que seria um nome do PT, posto que a grande maioria dos redatores do documento "A imaginação a serviço do país" era filiada ou ligada ao partido, além do que esse é um tema tradicionalmente caro às gestões municipais petitas, cuja principal referência é a passagem de Marilena Chaui pela Secretaria Municipal de Cultura de São Paulo, no governo de Luiza Erundina.

Contudo, a indicação acabou por ser a de Gilberto Gil, filiado ao Partido Verde, que passou a integrar a base de apoio do novo governo. Mais do que os compromissos com os novos aliados, pesou na escolha do músico baiano o seu capital simbólico de artista reconhecido internacionalmente e com bom trânsito no campo cultural brasileiro 4 .

\footnotetext{
4 Gil foi gestor da Fundação Cultural Gregório de Matos, em Salvador, entre janeiro de 1987 e julho de 1988, ano em que se elegeu vereador da cidade pelo PMDB. Suas reflexões politico-culturais desse período podem ser acessadas no livro que publicou junto com Antonio Risério, intitulado de $O$ poético e o politico (Gil; Risério, 1988).
} 
Como se dizia durante a sua gestão, tratava-se de "um ministro maior que o Ministério".

A nomeação de Gil e sua equipe provocou uma relação de poder não prevista no MinC, muitas vezes colocando em posições antagônicas seu grupo e aquele de gestores oriundos do PT, ainda que essas disputas não tenham sido publicizadas, apesar de se revelarem em momentos de ruptura, como veremos 5 . De todo modo, coube ao segundo grupo, entre outras funções, a de implementar o sistema, agora denominado Sistema Nacional de Cultura, sob coordenação de Márcio Meira ${ }^{6}$.

Meira tinha sido um dos cordenadores do programa de governo, coordenou a equipe de transição do MinC e era um dos nomes do PT cotado ao cargo de ministro da Cultura. Acabou por tornar-se secretário de Articulação Institucional (SAI), Secretaria criada na reestruturacão do MinC em 2003, com o objetivo de promover a articulação das políticas culturais das esferas federal, estadual e municipal, bem como do Distrito Fedeal e da sociedade civil e que teria no SNC seu principal instrumento.

Contudo, somente em 2005, foram tomadas as primeiras medidas mais efetivas no sentido de criação do SNC, como, por exemplo, o estabelecimento do Sistema Federal de Cultura, articulando todos os programas e ações do governo federal na área, e do "Protocolo de Intenções visando ao desenvolvimento de condições institucionais para a implantação do Sistema Nacional de Cultura”. O Protocolo funcionou como uma espécie de sondagem sobre a receptividade do SNC junto aos governos estaduais e municipais, posto que estes deveriam aderir ao documento e ao fazerem isso tinham que efetivar diversas obrigações que visavam a existência futura do Sistema. Entre as obrigações estavam incluídas a criação de orgão gestor, conselho, plano e formas de financiamento, além da realização de conferência de cultura7.

No mesmo ano, ocorreu a I Conferência Nacional de Cultura (CNC), precedida de centenas de conferências municipais e de dezenas de estaduais, configurando-se em um importante esforço de articulação do poder público nos três níveis federativos e com a sociedade. A CNC definiu como uma de suas prioridades a implementação do SNC.

\footnotetext{
5 O campo da política, mesmo na democracia que pretensamente responde à opinião pública, é, paradoxalmente, um espaço favorável à formação de discursos ocultos. Apesar de não ter a pretensão de explorar neste trabalho tais discursos, concordo com James Scott que a análise desse corpus discursivo é uma via que permite "reveler contradições e possibilidades, penetrando bem além da aparente tranquilidade que a acomodação à existente distribuição de poder, riqueza e estatuto muitas vezes apresenta" (Scott, 2013: 44).

${ }^{6}$ Márcio Meira é pesquisador do Museu Paraense Emílio Goeldi, instituição ligada ao Ministério da Ciência. Militante do PT no Pará, foi presidente da Fundação Cultural do Município de Belém entre 1998 e 2002, durante a gestão petista daquela capital.

7 Segundo o MinC, entre 2005 e 2006, 21 estados e 1967 municípios tinham aderido ao Protocolo (Brasil, 2013a).
} 
Também foi enviada ao Congresso Nacional pelo deputado Paulo Pimenta, do PT, a Proposta de Emenda à Constituição (PEC) 416/2005 que acrescenta o art. 216-A para instituir o SNC. Em estreita relacão com o SNC, o MinC ia construindo o Plano Nacional de Cultura cuja Emenda Constitucional n. 48 que o institui foi aprovada em $2005^{8}$.

Após a Conferência, o passo seguinte foi a realização, em 2006, das Oficinas do SNC que consistia de um ciclo de 30 módulos de oficinas de formação voltadas para os agentes culturais de municípios que tinham assinado ou manifestassem intenção de assinar o Protocolo. O objetivo era fortalecer o diálogo do MinC com os demais entes federados e entidades da sociedade civil sobre a ampliação da abrangência das diretrizes formuladas para o SNC (Lima, 2006).

Em 2007, no início do novo governo Lula e ainda com Gil à frente do MinC, o secretário Márcio Meira foi destituído do cargo, o que provocou reações contrárias por parte de vários agentes culturais do país, além do PT, que, por meio da Secretaria Nacional de Cultura, lançou uma nota sobre as demissões9. O documento ressalta a "contradição entre a avaliação interna e externa altamente positiva do desempenho dos dois [Meira e Grassi] - tanto no âmbito do MinC como na sociedade, entre artistas, produtores e gestores culturais, nos Estados e Municípios” e a saída forçada do Ministério.

Sobre Meira, a nota afirma que a condução dada por ele e sua equipe na SAI envolveu um "árduo processo de diálogo com secretários de Cultura de Estados e Municípios" visando a assinatura do Protocolo que possibilitará “a constituição pactuada do Sistema Nacional de Cultura, política estruturante indispensável para a consolidação do MinC como mecanismo republicano de formulação de políticas públicas de cultura duradouras para o país”10.

A nota conclui que a demissão afasta do MINC dois "servidores" que merecem respeito, pois, além de "competentes", eram "comprometidos com o programa apresentado pelo presidente Lula ao Brasil e que ao longo dos quatro anos de governo sempre foram leais ao presidente e ao ministro da Cultura”. Tal atitude destoaria do programa para a cultura "BRASIL: CULTIVAR A MEMÓRIA, INVENTAR O FUTURO”, que o candidato à reeleição Lula apresentou aos eleitores, em especial aos agentes culturais do país.

\footnotetext{
${ }^{8}$ O PNC só foi aprovado pelo Congresso Nacional em 2010, mesmo ano em que é sancionado pelo Presidente da Lula na forma da Lei no 12.343/2010.

9Além de Meira, foi também demitido Antônio Grassi, presidente da Fundação Nacional da Arte (Funarte). ${ }^{10}$ Além do esforço de constituição do SNC, a nota destaca ainda a participação de Meira na condução da I CNC e na elaboração da emenda que institui o PNC.
} 
A saída de Meira deve ser lida dentro da disputa interna ao MinC entre o grupo mais afinado aos programas de governo e aqueles agentes que não se sentiam compromissados com tais formulações, mesmo que não discordassem necessessariamente de todas elas. Glauber Piva, então Secretário Nacional de Cultura do PT, qualificou o processo de demissão de Meira e de Grassi como uma descontinuidade na gestão do MinC:

O ministro Gilberto Gil foi reconduzido ao cargo após um sonoro coro de 'Fica, Gil'. Petistas, Verdes, Azuis e outros tantos se juntaram num só coro na expectativa de que a gestão realizada no primeiro mandato continuasse e, de preferência, avançasse... Fizeram por compreender que a política de cultura comandada por Lula só teve sucesso pela qualidade do ministro e de sua equipe. Com isso, ao dizerem 'Fica, Gil', provavelmente estivessem dizendo 'Fiquem Gil e sua equipe'.

Meira, em entrevista concedida à pesquisadora Paula Félix Reis poucos meses após a sua saída do Ministério, mas já com outro cargo no governo Lula ${ }^{11}$, reconhece que Gil sempre apoiou publicamente o SNC, afirmando, inclusive, que era um dos programas prioritários. Contudo, diferencia o que pensava o ministro do conjunto de agentes que atuavam no Ministério, tanto que podia declarar "tranquilamente" que a proposta não tinha se consolidado plenamente, pois "um Sistema não se faz por decreto, é um processo de construção. Se ele não é visto dessa forma é melhor não fazer” (Meira apud Reis, 2008: 122). E reconhece que o processo não avançou muito nos quatro anos de governo como deveria, ou se queria, que tivesse avançado:

Poderia ter avançado muito, mas a vida é assim, nem sempre a gente consegue avançar tudo que poderia. Se não avançou foi por algum motivo, não é? Tem razões que explicam os avanços e recuos, eu acho que idealmente poderia ter avançado muito mais, mas as contradições da história são assim mesmo. Muita coisa avança e outras coisas não avançam tanto. Mas eu espero, pelo menos, que o que a gente avançou e possa avançar ainda mais até o final do governo Lula, nesse segundo mandato, possa ser forte o suficiente para dar continuidade depois. (Meira apud Reis, 2008: 123-124).

Meira, contudo, relativiza as diferenças e disputas internas ao MinC como algo "natural”, pois diante do projeto comum, "o fortalecimento da política cultural como política pública de Estado”, se teria construído “um acordo no Ministério” (Meira apud Reis, 2008: 123). O que Meira parece desconhecer é justamente a dimensão hegemônica e agonística do poder, da qual não está ausente a paixão, e, portanto, não

${ }^{11}$ É importante esse contexto para situarmos o depoimento de Meira que dificilmente, nessas condições, revelaria os bastidores, ou os "discursos ocultos", para fazer referência à Scott (2013), que envolveram a sua demissão. 
estão garantidos os consensos construídos em torno de objetivos e argumentos racionais (Mouffe, 2009).

No lugar de Meira, o ministro nomeou Marco Acco que acumulou o cargo com o de secretário de Fomento e Incentivo à Cultura (SEFIC) ${ }^{12}$, uma Secretaria que, responsável pelos incentivos fiscais e pelo FNC, demandava de seu titular um dedicacão intensa. Assim, podemos entender porque os passos seguintes de maior relevância no que se refere diretamente ao SNC só vão se dar em 2009. Nesse ínterim, como define Leonardo Brant, no site Cultura e Mercado, "o Sistema ficou sem pai, nem mãe" e seu maior defensor foi João Roberto Peixe, integrante do Conselho Nacional de Política Cultural, que lutou pela retomada do programa e acabou por assumir posteriormente a coordenação do SNC.

Em entrevista concedida a mim, Peixe confirma que com a saída de Meira "a questão do Sistema ficou quase que paralisada nos dois primeiros anos da segunda gestão [do governo Lula]”, e que só foi retomada quando, em agosto de 2008, Juca Ferreira assume o Ministério e Silvana Meireles a $\mathrm{SAI}^{13}$, mas ainda assim "em um patamar de estrutura e de condições bem abaixo do que existia no primeiro governo"14.

Naquele ano, ocorreram a aprovação no Conselho Nacional de Política Cultural do documento "Proposta de Estruturação, Institucionalização e Implementação do Sistema Nacional de Cultura"; a realização de uma nova rodada de seminários sobre o SNC em 24 estados, envolvendo gestores e conselheiros de cultura de 2.323 municípios; e a retomada do pacto federativo, ensaiado em 2005 com o Protocolo de Intenções, com a assinatura do "Acordo de Cooperação Federativa do SNC". Contudo, até o fim do governo Lula (2010), somente $363(6,5 \%)$ Municípios e 1 (3,7\%) Estado tinham formalizado sua integração ao Sistema.

\footnotetext{
12 Economista de formação, Marco Acco entrou no MinC em 2004 como assessor de políticas culturais. Entre 2006 e 2007, assumiu a SEFIC, substituindo Sérgio Xavier. Segundo André Fonseca, do site Cultura e Mercado, a saída de Xavier e de outros membros do primeiro escalão do Ministério deveu-se "a uma necessidade de maior alinhamento com o núcleo duro do MinC, comdandado pelo Secretário-executivo Juca Ferreira, que chega ao último ano de mandato mais fortalecido". (Sérgio Xavier deixa o MinC anunciando novo recorde). Acco retornou ao MinC em 2011 como secretário Executivo Adjunto do ministro Juca.

13 Silvana Mireles é servidora da Fundação Joaquim Nabuco, do Ministério da Educação, com especialização na área de política cultural e Integrou a equipe da SAI durante a gestão de Meira. Em depoimento à Ana Lúcia Aragão, Lia Calabre, pesquisadora da Fundação Casa Rui Barbosa e integrante da Comissão Executiva da I CNC, situa que, na divisão interna de tarefas entre a equipe da SAI, Meireles "fazia mais articulação institucional, então ela era a pessoa do diálogo com instituições então ela era a pessoa que tinha contato com o SESC, por exemplo" (Calabre apud Aragão, 2013: 143), um papel que a credenciou para o cargo de secretária.
}

14 Entrevista concedida ao autor. Salvador, 13 de setembro de 2013. 
No documento "Proposta...", que só foi publicado pelo MinC em 2011, a então ministra da Cultura, Ana de Hollanda, reconhecia que o SNC, desde 2003, avançou, mas "também enfrentou recuos, provocados, na maioria das vezes, pelas incertezas sobre a melhor forma de organizar as novas atribuições do poder público na área da cultura" (Hollanda, 2011: 13). Por sua vez, Peixe (2011), que assume a SAI na gestão de Hollanda ${ }^{15}$, apontava, entre os desafios para a implantação do SNC, a descontinuidade administrativa e a competição no interior do próprio governo.

Em março de 2010, a II Conferência Nacional de Cultura confirma como uma de suas 32 propostas prioritárias, "Consolidar, institucionalizar e implementar o Sistema Nacional de Cultura (SNC)" ${ }^{16}$. Nesse mesmo ano, o MinC elabora as "Guias de Orientações do SNC", voltados para estados e municípios e que são disponibilizados on-line no blog do SNC.

\section{Governo Dilma e SNC: continuidade ou solução de continuidade?}

Em 2011, no governo Dilma, e com Ana de Hollanda como Ministra da Cultura, a SAI passa por uma reformulação na qual, significativamente, a implantação do SNC passa a ser seu foco principal. É também sintomático que Roberto Peixe, que estava à frente do SNC como Coordenador Geral de Relações Federativas e Sociedade da SAI, assuma a Secretaria. Este momento configura-se, portanto, como um marco no sentido do Sistema voltar a ocupar uma centralidade entre os projetos do Ministério, lugar que já tinha ocupado no primeiro governo Lula, durante a passagem de Meira e sua equipe.

No lugar de Peixe como coordenador do SNC, assume Bernardo Novais da Mata Machado que já vinha trabalhando junto ao Sistema desde o período de Silvana Meireles. Em entrevista ao Observatório da Diversidade Cultural, em março de 2012, Mata Machado reconhece que houve um “crescimento muito expressivo" de adesões ao SNC e diagnostica as causas:

aos esforços da Secretaria de Articulação Institucional, que foi reestruturada no começo do ano para concentrar-se nesse objetivo; à presença constante de seus dirigentes em encontros para debater o Sistema Nacional de Cultura em todo o país; à publicação do "Guia de Orientações para os Municípios; SNC - Perguntas e Respostas”, que disseminou de forma didática as vantagens e os procedimentos de integração ao Sistema; e à percepção, pelos entes federados, de que as políticas

\footnotetext{
15 João Roberto Peixe é arquiteto, designer e gestor cultural. Militante do PT pernambucano do qual foi um dos fundadores, atuou como secretário de Cultura de Recife entre 2001 e 2008.

16Ver o "EIXO 5: GESTÃO E INSTITUCIONALIDADE DA CULTURA SUB-EIXO: 5.1 - Sistemas Nacional, Estaduais, Distrital e Municipais de Cultura" do documento "Conferindo os conformes. Resultados da II Conferência Nacional de Cultura”.
} 
públicas caminham, progressivamente, para se estruturarem com base em sistemas nacionais, aí incluídas as transferências de recursos fundo a fundo.

Em outro momento da entrevista, Mata Machado destaca a aprovacão nas diretrizes para 2012 de 40\% do valor global do Fundo Nacional de Cultura (FNC) para "transferência aos entes federados que aderiram ao Sistema Nacional de Cultura, com prioridade para os que já constituíram o seu Sistema de Cultura e, a seguir, aos que ainda estão em processo de constituição". Como observa, desde que se o iniciou o processo de implantação do SNC, é "a primeira vez que o MinC condiciona a transferência de recursos à constituição de sistemas estaduais e municipais de cultura" ${ }^{17}$. Por conta desse fato, avalia que a adesão "tende a crescer muito rapidamente" e para responder a esse desafio, em cooperação com a Unesco, o MinC contratou consultores para orientar e acompanhar a implantação do SNC nos estados e municípios.

Nos anos de 2011 e 2012, foram publicados e distribuídos nacionalmente o documentobase do SNC, intitulado "Estruturação, Institucionalização e Implementação do SNC", (20.0000 exemplares) e as cartilhas "Guia de Orientações do SNC (Perguntas e Respostas) - para Municípios" (50.000 exemplares) e "Guia de Orientações do SNC (Perguntas e Respostas) - para os Estados“ (10.00o exemplares). O esforço visível do MinC é publicizar o máximo possível o Sistema com o intuito de garantir o maior número de adesões. O retorno foi o crescimento de 363 municípios e 1 estado no fim de 2010 para 1407 municípios, 22 estados e o Distrito Federal, em dezembro de 2012, integrados ao SNC por meio da assinatura do Acordo de Cooperação Federativa (Brasil, 2013a: 08).

Em 2012, foram dados dois passos fundamentais para a efetiva institucionalizacão do SNC: o encaminhamento à Presidência da República para posterior envio ao Congresso Nacional do Projeto de Lei do Sistema Nacional de Cultura e a aprovação e promulgação pelo Congresso Nacional da Emenda Constitucional $n^{\circ}$ 71/2012 que introduz o Sistema Nacional de Cultura na Constituição Federal. A Emenda, que resulta originariamente da PEC 416/2005, acrescenta o Art. 216-A que fixa:

O Sistema Nacional de Cultura, organizado em regime de colaboração, de forma descentralizada e participativa, institui um processo de gestão e promoção conjunta de políticas públicas de cultura, democráticas e permanentes, pactuadas entre os entes da Federação e a sociedade, tendo por objetivo promover o desenvolvimento humano, social e econômico com pleno exercício dos direitos culturais.

${ }_{17}$ Contudo, somente em 2014, como se verá, é que começa a transferência de recursos por meio do SNC. 
Também no mesmo ano, inicou-se o reforço do apoio técnico da SAI à elaboração dos planos estaduais e municipais de cultura no sentido de disseminar as bases do Sistema nestes dois níveis da Federação.

O ápice desse processo no governo Dilma, mas já na gestão da ministra Marta Suplicy, foi a realização da III Conferência Nacional de Cultura, que ocorreu entre 27 de novembro e 01 de dezembro de 2013, e cujo tema era, significativamente, "Uma política de estado para a cultura. Desafios do Sistema Nacional de Cultura” (Brasil, 2013b), antecipada pelas conferências estaduais e municipais que contaram com a participação de milhares de pessoas.

Até aquele momento já tinham aderido ao SNC todos os 26 estados brasileiros e respectivas capitais, além do Distrito Federal, bem como 2.068 municípios ${ }^{18}$. Assim, é possível afirmar que houve em torno do SNC um processo de hegemonização, ou seja, de construção de uma ampla identidade social com essa política cultural, tendo o MinC como agente principal na articulação das diferentes posições de sujeito, tornando-o uma proposta consensual nos campos político e cultural brasileiros (Barbalho, 2014).

No documento "III Conferência Nacional de Cultura: uma política de estado para a cultura. Desafios do Sistema Nacional de Cultura. Texto-base" encontram-se os 19 objetivos definidos de acordo com a missão do MinC de "garantir a todos os cidadãos brasileiros o pleno exercício dos seus direitos culturais”. Divididos em quatro grandes áreas de atuação, Criação/Produção/Desenvolvimento; Difusão e Acesso à Cultura; Memória e Diversidade Cultural; e Planejamento e a Gestão, os objetivos que se relacionam mais diretamente ao SNC estão nessa última:

(15) Assegurar a participação da sociedade na formulação e implementação das políticas; (16) Promover a integração com os entes federados na execução da política; (17) Integrar e consolidar as políticas de fomento e incentivo no sistema MinC; (18) Aperfeiçoar os marcos regulatórios; e (19) Aperfeiçoar os processos de monitoramento e fiscalização (Brasil, 2013b: 02).

Por sua vez, levando em consideração que "Planejar é, sobretudo, priorizar", o MinC elegeu 4 programas: 1. Criar e descentralizar equipamentos culturais por meio da construção dos Centros de Artes e Esportes Unificados (CEUs); 2. Implantar o ValeCultura; 3. Fortalecer a presença do Brasil no mundo por meio do soft power; e 4. Implantar o SNC, posto que "a articulação entre a Sociedade e o Estado (representado pelos entes federados) é a garantia da construção de políticas culturais com bases sólidas e permanentes" (Brasil, 2013b: 03).

${ }^{18}$ O que equivale a 37,2\% dos municípios brasileiros. Dados atualizados pelo MinC em 19.11.2013. 
O texto base da III CNC se organiza em 4 eixos: I - IMPLEMENTAÇÃO DO SISTEMA NACIONAL DE CULTURA; II - PRODUÇÃO SIMBÓlLICA E DIVERSIDADE CULTURAL; III - CIDADANIA E DIREITOS CULTURAIS e IV - CULTURA COMO DESENVOLVIMENTO SUSTENTÁVEL. O eixo I tem como foco os "Impactos da Emenda Constitucional do SNC na organização da gestão cultural e na participação social nos três níveis de governo (União/Estados/ Distrito Federal e Municípios)" (Brasil, 2013b: 04).

Os quatro desafios colocados a esse eixo são: 1 - Marcos Legais, Participação e Controle Social e Funcionamento dos Sistemas Municipais, Estaduais/ Distrito Federal e setoriais de cultura, de acordo com os princípios constitucionais do SNC; 2 Qualificação da Gestão Cultural: Desenvolvimento e Implementação de Planos Territoriais e Setoriais de Cultura e Formação de Gestores, Governamentais e Não Governamentais e Conselheiros de Cultura; 3 - Sistemas de Informação Cultural e Governança Colaborativa; 4 - Fortalecimento e Operacionalização dos Sistemas de Financiamento Público da Cultura: Orçamentos Públicos, Fundos de Cultura e Incentivos Fiscais.

A III CNC elegeu 64 diretrizes, com 20 dentre elas consideradas como prioridades, divididas equitativamente entre os quatro eixos referidos acima. A cinco diretrizes priorizadas no eixo I foram: 1a) "Que o Congresso Nacional aprove com urgência a PEC 150"; 2a) "Garantir que pelo menos 10\% dos recursos do Fundo Social do Pré-Sal sejam destinados à Cultura"; 3a) "Aprovar com urgência no Congresso Nacional Projeto de Lei Complementar (PLC) 383/2013 de regulamentação do SNC (...) e apoiar a implantação e o pleno funcionamento dos seus componentes, em todos os níveis da Federação"; 4a) "Criar, desenvolver, fortalecer e ampliar as estratégias para a formação e capacitação em gestão cultural de forma permanente e continuada”; e 5a) 'Fortalecer o Fundo Nacional de Cultura, como principal mecanismo de financiamento público da cultura”.

Não é o caso de discutir aqui tais diretrizes, mas é relevante ressaltar que em uma Conferência que tinha como tema central o SNC e sendo este um dos quatro programas prioritários do MinC, o fato do eixo I ter tido a mesma quantidade de diretrizes aprovadas dos outros eixos revela que, nesse momento, o Sistema não alcançou um patamar de importância diferenciado dos outros eixos, programas e acões do Ministério.

Possivelmente, uma pesquisa sobre os temas que mais agendaram a gestão de Marta Suplicy tenha como resultado as outras três prioridades elencadas: os CEUs, o Vale- 
Cultura e o debate acerca do soft power. Do mesmo modo que talvez os temas dos direitos autorais e da economia criativa tenham preponderado na gestão Ana de Hollanda. Contudo, retomando a tese defendida nesse artigo, o SNC continuou sendo implantado, sem sofrer de maiores resistências internas, quando da primeira gestão de Gil, ou de solução de continuidade, quando do período imediatamente posterior à demissão de Meira do MinC.

Isso ocorre mesmo com a saída de Peixe da SAI em junho de 2013. Em depoimento ao Jornal do Commercio, o gestor afima que saiu com o sentimento de "dever concluído" e que a troca de secretários é um movimento "natural" da nova ministra que quer montar a sua equipe de confiança: "Marta falou que o trabalho que eu tinha feito era reconhecido pelo ministério. Até porque o Sistema Nacional de Cultura está em um bom patamar agora, fruto de um trabalho nacional iniciado desde 2002, com pausas, mas levado a frente por muitos".

Contudo, em entrevista para o Blog do Jamildo, Peixe é mais dúbio sobre o processo e deixa transparecer sinais de discursos ocultos ao público. Perguntado se houve "ruídos" com a minstra, responde:

Quem poderia explicar isso melhor é ela. Na verdade, assim, pelo menos até agora a equipe que montei continuou. Não sei se continuará. A ministra Marta foi progressivamente mudando toda equipe do ministério. E estranhamente ela foi mudando todos os dirigentes do PT que ocupavam postos nos ministério. A única pessoa que ela manteve foi o Manoel Rangel (PCdoB) na presidência da Ancine. Todos os dirigentes ou foram demitidos ou se anteciparam e pediram para sair, caso de Sérgio Mamberti.

No lugar de Peixe, assume a SAI Marcelo Pedroso que só fica até julho do mesmo, quando vai para o cargo de secretário Executivo do Ministério ${ }^{19}$. Em seu lugar, assume Bernardo da Mata Machado que, como vimos, já atuava junto ao SNC desde o governo Lula e deu continuidade ao que vinha sendo feito por Peixe ${ }^{20}$.

No último ano de gestão de Marta Suplicy, Mata Machado inicia o processo de transferência de recursos do MinC via SNC aos estados e municípios. Em depoimento institucional à MinC TV, o secretário assume que este será o principal desafio de $2014 \mathrm{e}$ de fato a grande novidade no que diz respeito ao Sistema, posto que os outros desafios

\footnotetext{
19 Marcelo Pedroso é funcionário da Prefeitura Municipal de Santos e foi secretário de Turismo de Guarujá. Antes de ir para o MinC, estava há sete anos diretor da Embratur.

${ }^{20}$ Mata Machado é historiador e cientista politico, com especialização em gestão cultural, e pesquisador da Fundação João Pinheiro (MG). Também atua como ator e diretor de teatro.
} 
se relacionam com o aprofundamento e/ou manutenção de ações que já vinham ocorrendo como a criação das leis estaudais e municipais de implementação de sistemas de cultura; o apoio à elaboração de planos estaduais e municipais de cultura; os cursos de formação de gestores e conselheiros de cultura.

O instrumento que o MinC criou para efetivar a transferência de recursos foi um edital, lançado em março, "Processo seletivo de fortalecimento do Sistema Nacional de Cultura”, ou mais especificamente, um "processo seletivo de apoio a projetos do Fundo Nacional da Cultura ao Orçamento-Geral da União de 2014, destinado aos entes federados estaduais e distrital". O edital, além de atender aos ensejos de repasse de verba via Sistema, tanto que só podiam concorrer os governos estaduais que tinham instituído seus sistemas por lei própria, também procurava responder às metas estabelecidas no $\mathrm{PNC}^{21}$.

O total de recursos disponibilizados foi de $\mathrm{R} \$ 30$ milhões distribuídos em 3 eixo relacionados com as metas do PNC a serem atendidas: EIXO 01 - Promoção da Diversidade Cultural Brasileira. (Meta 6); EIXO 02 - Fomento à Produção e Circulação de Bens Culturais. (Metas 22 e 24); EIXO 03 - Implantação, Instalação e Modernização de Espaços e Equipamentos Culturais. (Metas 29, 30, 31, 32,33 e 34) ${ }^{22}$.

\section{Conclusão}

O SNC situa-se entre os programas mais ambiciosos do MinC, por institucionalizar a cultura como um sistema federativo de políticas públicas. Apesar de sua importância, como se observou, o processo de implantação do Sistema passou por momentos críticos que colocou em xeque sua efetivação durantes os governos Lula, em especial no início do segundo mandato. Isso se deveu aos antagonismos e disputas que fazem parte de toda relação de poder e que foram se equilibrando ao longo dos anos.

Revelador, nesse sentido, é a trajetória dos principais agentes envolvidos nos períodos de maior dinamicidade do SNC, ou seja, Márcio Meira e João Roberto Peixe, ambos militantes históricos do PT, com experiências secretários municipais de cultural e integrantes da coordenação de redação do documento "A imaginação a serviço do país".

Somente no governo Dilma, o SNC ganha o impulso que os agentes político-culturais, em especial aqueles ligados ao PT, reinvidicavam desde a gestão Gil, a despeito das trocas das ministras e dos secretários da SAI. Comprovam tal tese a reestruturação da

\footnotetext{
${ }^{21}$ Foram nove as metas do PNC contempladas nesse edital: 6, 22, 24, 29, 30, 31, 32, 33 e 34 .

${ }_{22}$ Foram classificados para a fase preliminar 5 projetos para o eixo 1, propostos pelos estados da Bahia, Rio Grande do Sul, Ceará, Roraima e Acre; 6 projetos para o eixo 2, propostos pelos estados da Bahia, Rio Grande do Sul, Ceará, Roraima, Paraíba e Acre; e 5 projetos para o eixo 3, propostos pelos estados da Bahia, Rio Grande do Sul, Ceará, Paraíba e Acre.
} 
SAI que passa ter como foco a efetivação do SNC; o intenso processo de adesão ao Sistema que antecede a realização da III CNC, que compreendo como um processo de hegemonização em torno do programa; e por fim, a concretização, em curso, de transferência de recursos por meio do SNC.

Certamente, o Sistema não está implantado e muito esforço político e institucional deverá ser dispendido para que, de fato, se torne um programa relativamente estável. E aqui entra o papel decisivo dos agentes culturais externos ao governo e de seus movimentos. Em outras palavras, caberá, em grande parte, ao modo como a sociedade vem se apropriando, ou não, do Sistema a continuidade das ações, em especial se ocorrer uma mudança na conjuntura político-partidária que há doze anos conduz o poder executivo do país.

A necessidade da efetiva incorporacão do SNC pela sociedade torna-se ainda mais relevante quando, no último ano do Governo Dilma observamos, em um contexto mais amplo, a reação por parte do campo político-partidário, mas também de associações de classe, contrária à Política Nacional de Participação Social instituída pelo Decreto n. 8.243/2014. Em manifesto lançado por intelectuais a favor do referido decreto, o texto se referencia nos "dispositivos constitucionais essenciais ao exercício da democracia, que prevêem a participação social como diretriz" dos sistemas de políticas públicas, entre os quais é incluído o de cultura.

Em um contexto mais específico, porém inserido nas disputas eleitorais de 2014, observa-se algumas expressões públicas de descontentamento em relação ao SNC. Por exemplo, em uma postagem no sítio eletrônico do Consórcio dos Municípios da Mata Norte e Agreste Setentrional de Pernambuco (COMANAS), afirma-se que a adesão ao Sistema "ainda é um desafio para muitos Municípios do Noroeste de Minas Gerais", como se constatou em audiência pública, promovida pela Comissão de Cultura da Assembleia Legislativa, realizada em 9 de junho, em Paracatu (MG).

Situação que, por sua vez, não é exclusiva dos municípios mineiros, pois “outras regiões do país são obrigadas a adotar as prerrogativas de um sistema que se autodenomina democrático, mas que (...) determina "certas exigências" para os repasses de recursos a Estados e Municípios”. Assim, na avaliação da Confederação Nacional de Municípios (CNM), "o maior desafio aos Municípios brasileiros é apresentar alternativas ao modelo imposto pelo Minc, pois há um hiato entre o discurso oficial e a efetividade das políticas públicas de cultura do país”.

Esta expressão de insatisfação, envolvendo uma organização de peso político como a $\mathrm{CNM}$, sinaliza que o processo de hegemonização obtido no período imediatemnte 
anterior à III CNC pode estar em crise, o que necessitaria de uma nova articulação, sem dúvida envolvendo o máximo de agentes político-culturais externos ao governo.

\section{Referências Bibliográficas}

Aragão, Ana Lúcia (2013) O direito de participação na vida cultural do Brasil no governo Lula. Dissertação. Universidade Federal da Bahia. Instituto de Humanidades, Artes e Ciências. Programa Multidisciplinar de Pós-Graduação em Cultura e Sociedade.

Barbalho, Alexandre (2014) Em busca da institucionalização nunca tida: a construção do Sistema Nacional de Cultura. Texto apresentado no II Congresso Mundial de Comunicação Ibero-americana - COMFIBERCOM. Braga: Universidade do Minho.

(1998) Relações entre Estado e cultura no Brasil. Ijuí: Unijuí.

Barbalho, Alexandre; Barros, José Márcio \& Calabre, Lia (org.) (2013) Federalismo e políticas culturais no Brasil. Salvador: UFBA, pp. 115-130.

Bourdieu, Pierre (2012) Sur l'Etat: Cours au College de France. 1989-1992. Paris: Seuil.

(1996) Razões práticas: sobre a teoria da ação. Campinas: Papirus.

Brasil. Ministério da Cultura (2013a) Oficina de implementação de sistemas estaduais e municipais de cultura. Brasília: MinC.

http://www.cultura.gov.br/documents/10907/963783/Apostila+-

+Oficina+de+Implementação+dos+Sistemas+de+Cultura.pdf/52b7f7bb-da35-4d1ca18d-c5f7bacf9624 (consultado em 31 outubro de 2014).

Ministério da Cultura (2013b). III Conferência Nacional de Cultura: uma política de estado para a cultura. Desafios do Sistema Nacional de Cultura. Texto-base. Brasília:

MinC. http://www.guiacultural.unicamp.br/sites/default/files/textobaseiiiconfnaccultura.pdf (consultado em 31 outubro de 2014).

Cury, Cláudia Engler (2002) Políticas culturais no Brasil: subsídios para lembrar construções de brasilidade. Tese (doutorado) - Universidade Estadual de Campinas, Faculdade de Educação. Campinas. 161 pags. 
Coliçação Lula Presidente (2002). A imaginação a serviço do país. Programa de Políticas Públicas de Cultura. São Paulo: Comitê Lula Presidente, 2002. http://www.construindoumnovobrasil.com.br/images/downloads/aimaginacaoaservic odobrasil.pdf (consultado em 31 outubro de 2014).

Elias, Norbert (2008) Introdução à sociologia. Lisboa: Edições 70.

Gil, Gilberto \& Risério, Antonio (1988) O poético e o politico. São Paulo: Paz e Terra.

Hollanda, Ana de (2011) "O pleno exercício dos direitos culturais", in Estruturação, Institucionalização e Implementação do Sistema Nacional de Cultura. Brasília: MinC, pp.13.

Lima, Roberto (2006) “Apresentação. Oficinas do SNC", in Calabre, Lia (Org.) Oficinas do Sistema Nacional de Cultura. Brasília: Ministério da Cultura, pp. 09-24. http://www2.cultura.gov.br/upload/Projeto Oficinas Miolo 1156970790.pdf (consultado em 31 outubro de 2014).

Meira, Márcio \& Gazzinelli, Gustavo (2006) "Sistema Nacional de Cultura”, in Calabre, Lia (org.) Oficinas do Sistema Nacional de Cultura. Brasília: Ministério da Cultura, pp. 09-24. http://www2.cultura.gov.br/upload/Projeto Oficinas Miolo 1156970790.pdf (consultado em 31 outubro de 2014).

Mouffe, Chantal (2009) The democratic paradox. Londres: Verso.

Peixe, João Roberto (2011) “A importância estratégica do sistema nacional de cultura”, in Estruturação, Institucionalização e Implementação do Sistema Nacional de Cultura. Brasília: MinC, p. 14.

Apresentação (2013a) "O sistema nacional de cultura alcança novo patamar”, in Oficina de implementação de sistemas estaduais e municipais de cultura. Brasília: MinC. $\quad$ http://www.cultura.gov.br/documents/10907/963783/Apostila++Oficina+de+Implementação+dos+Sistemas+de+Cultura.pdf/52b7f7bb-da35-4d1ca18d-c5f7bacfg624 (consultado em 31 outubro de 2014).

Reis, Paula Félix dos (2008) Políticas culturais do Governo Lula: análise do Sistema e do Plano Nacional de Cultura. Dissertação apresentada ao Programa Multidisciplinar de Pós- Graduação em Cultura e Sociedade da Universidade Federal da Bahia.

Rubim, Albino (2011) As Políticas Culturais e o Governo Lula. São Paulo: Fundação Perseu Abramo. 
(org.) (2010) Políticas Culturais no Governo Lula. Salvador: UFBA.

Scott, James C (2013) A dominção e a arte da resistência. Discursos ocultos. Liboa: Letra Livre.

\section{Sites Consultados}

http://g1.globo.com/Noticias/Politica/o,AA1413429-5601,00-

$\underline{\text { SECRETARIA+DO+PT+DIVULGA+NOTA+SOBRE+DEMISSOES+NA+CULTURA.ht }}$ $\underline{\mathrm{ml}}$.

http://www.cartamaior.com.br/?/Editoria/Midia/Mudancas-turbulentas-noMinisterio-da-Cultura/12/12366.

https://www.culturaemercado.com.br/noticias/sergio-xavier-deixa-o-mincanunciando-novo-recorde

http://www.culturaemercado.com.br/analise/a-retomada-do-sistema-nacional-decultura/

http://pnc.culturadigital.br/wp-content/uploads/2012/10/1-Resultados-IIConferência-Nacional-de-Cultura.pdf.

http://observatoriodadiversidade.org.br/site/“a-expectativa-e-que-o-snc-se-torne-umpoderoso-instrumento-de-protecao-e-promocao-da-diversidade-cultural-brasileira"

http://www.planalto.gov.br/ccivil 03/constituicao/Emendas/Emc/emc71.htm http://www.cultura.gov.br/documents/10907/1030302/Quantitativo+de+Munic\%C3 \%ADpios+e+Estados+com+Acordo.pdf/82735882-d103-4953-bdba-c031doegfoo8. http://www.cultura.gov.br/documents/10907/945028/Propostas+aprovadas+na+III+ CNC/d4021391-7293-4005-bb6c-043bfd79ead6

http://jconline.ne10.uol.com.br/canal/cultura/noticia/2013/03/29/joao-robertopeixe-diz-que-saiu-do-minc-com-dever-concluido-78014.php

http://blogs.ne10.uol.com.br/jamildo/2013/05/12/pt-deve-apontar-as-falhas-dagestao-eduardo-diz-roberto-peixe https://www.youtube.com/watch?v=kpdw345U5c4 http://www.cultura.gov.br/documents/10180/o/editalfinalsnc/3obf6f62-f622-4d28- 
bb31-4b3f3ebbdcb7.

https://docs.google.com/forms/d/1zdr9gvJvBzaIaIrTnHOEthYpBoQicogZq893GA1y2 do/viewform? $\mathrm{c}=0 \& \mathrm{w}=1$

http://www.comanas.pe.gov.br/index.php/noticias/747-sistema-nacional-de-culturaadesao-e-obtencao-de-recursos-e-um-desafio-a-ser-enfrentado-pelos-municipios. http://www.cultura.gov.br/documents/10883/1170919/RESULTADO+PRELIMINAR+ -+FASE+CLASSIFICAÇÃO+-+LISTA.pdf/2329cb5c-9f12-436c-9ebd-ofe214e79e54

\begin{abstract}
Alexandre Barbalho: Doutor em Comunicacão e Cultura Contemporâneas pela Universidade Federal da Bahia e estágio pós-doutoral na Universidade Nova de Lisboa. Professor dos Programas de Pós-Graduação em Políticas Públicas da Universidade Estadual do Ceará e em Comunicação da Universidade Federal do Ceará. Líder do Grupo de Pesquisa "Políticas de Cultura e de Comunicação" - CULT.COM. Autor e organizador, entre outras, das seguintes obras: Relações entre Estado e cultura no Brasil; A modernização da cultura; Brasil, brasis: identidades, cultura e mídia e A criação está no ar; juventudes, política, cultura e mídia. E-mail: alexandrealmeidabarbalho@gmail.com
\end{abstract}

